\section{The use of midazolam in the preterm neonate}

\section{J.N.van den Anker and P. J.J.Sauer}

Department of Paediatrics, Sophia Children's Hospital, Gordelweg 160, P.O. Box 70029, NL-3000 LL Rotterdam, The Netherlands

Received September 4, 1991 / Accepted September 6, 1991

Sir: Numerous recent reports have demonstrated the occurrence of pain and stress and their many effects in critically ill neonates. They emphasize the importance of analgesia and sedation in such patients, usually achieved with an opiate/benzodiazepine combination $[1,4]$. The use of diazepam, a long-acting benzodiazepine, during the perinatal period is limited by its long elimination half-life and by the accumulation of a hypnotic metabolite, N-desmethyldiazepam, which leads to prolonged sedation. By contrast, in adults midazolam is a short-acting benzodiazepine, and its major metabolite, 1-hydroxymidazolam, is less active than the parent drug. This therefore seemed a promising sedative drug for preterm neonates and an increase in the use of midazolam in neonatal intensive care units has been observed, although very limited data concerning pharmacokinetics and pharmacodynamics of midazolam in the preterm neonate are available. Only Jacqz-Aigrain [3] studied pharmacokinetics of midazolam in ten critically ill neonates (gestational age: $34-41$ weeks). They showed an elimination half-life of $6.52 \mathrm{~h}$, indicating that midazolam in preterm neonates is not really short-acting. Furthermore in this study there was no clinical evidence of any adverse effect.

We have observed several adverse effects in premature neonates with a gestational age below 32 weeks. Heart rate and arterial blood pressure decreased directly following an intravenous bolus injection of $0.2 \mathrm{mg} / \mathrm{kg}$ midazolam, but the most disturbing observation was the appearance of involuntary epileptiform movements lasting for $15-30 \mathrm{~s}$.

The pathogenesis of this phenomenon is speculative, but perhaps in these preterm infants the decrease in arterial pressure and heart rate have also an impact on cerebral blood flow or there is a direct effect of midazolam on the brain.

Before the more frequent use of this drug in our neonatal intensive care units is advocated, the pharmacokinetics and pharmacodynamics (i.e. using 24-h EEG monitoring [2]) of midazolam should be studied.

\section{References}

1. Anand KJS, Hickey PR (1987) Pain and its effects in the human neonate and foetus. N Engl J Med 9:1321-1329

2. Buhrer M, Maitre PO, Crevoisier C, Stanski DR (1990) Electroencephalographic effects of benzodiazepines. II. Pharmacodynamic modeling of the electroencephalographic effects of midazolam and diazepam. Clin Pharmacol Ther 48:555-567

3. Jacqz-Aigrain E, Wood C, Robieux I (1990) Pharmacokinetics of midazolam in critically ill neonates. Eur J Clin Pharmacol 3: 191-192

4. Willatts SM (1985) Intravenous sedation by infusion on the intensive care unit. Br J Parent Ther 1:13-17 